\title{
A Mechanism for Using Renewable Energy Applications in Remote Areas
}

\author{
Safwat Abdel Fattah Seleem \\ High Institute of Engineering, 15 th May City, \\ Former General Manager, \\ Safwat.seleem@yahoo.com
}

\begin{abstract}
Currently our world is facing the challenge of natural resources depletion, specifically the depletion of fossil fuel resources. Accordingly, the implementation of sustainable energy sources is no longer a luxury, but a key issue for survival. Egypt is one of the most fortunate locations when it comes to renewable energies, such as wind and the sun but implementation remains lacking. This paper addresses this matter by offering simple applicable solutions for remote areas, such as Al-Wadi Al-Jadid and Sinai. The idea is based on creating a selfsustaining simple closed system that can be replicated in different settlements, which offers prosperity for the local communities.
\end{abstract}

The proposed system will be designed to address the technical, financial and social barriers that prevent renewable energies from becoming widespread in Egypt. Such a system would consist of financial institutions, suppliers, local technical capacity building and local awareness raising and education. In addition, they use fly ash material in construction of different projects that contains concrete, plaster, and bricks. The use of fly ash material aims at saving energy and reduces the use of cement, as the fly ash replaces about $25 \%$ of cement quantity in concrete and plaster works and about $60 \%$ of brick ingredients.

Accordingly, the use of fly ash material leads to reducing the emission of $\mathrm{CO} 2$ resulting from the factories of cement. Simply, in order to spread the use of renewable energy on a large scale, the community as a whole must benefit and private individuals must also benefit by being able to make life easier and reduce pollution levels.

Keywords - Renewable energy, Sustainable, Friendly environmental concrete, Fly ash, Remote areas.

\section{INTRODUCTION}

One of the main concerns in Egypt is to guarantee modern electricity resources for all citizens. This target matches with the concept of sustainable development, which is defined as "development that meets the needs of the present without compromising the ability of future generations to meet their own needs" [1]. The main factor in attaining sustainability is how to implement it effectively. The key points are the design of a realistic work system that meets the needs of the society and that can be easily implemented. The awareness of the community plays an important role as well. This is where the idea of sustainable communities starts emerging.

Sustainable communities can be defined through different ways; one common definition is "communities that meet the diverse needs of existing and future residents, their children and other users, contribute to a high quality of life and provide opportunity and choice. They achieve this in ways that make effective use of natural resources, enhance the environment, promote social cohesion and inclusion and strengthen economic prosperity" [2]. Figure 1 represents the main components of sustainable communities.

In this regard, the idea of the paper has been highlighted. It aims to create a sustained community based on available local resources and components. Providing vulnerable underprivileged rural households with a sustainable and environmentally friendly source of energy will improve the quality of living. It will allow for covering their basic needs of food, safety and security by making the operation of small fridges possible and providing a storage facility.

This will also allow for reducing transportation expenditures and the use of and dependency on fossil fuels. Having access to electricity, saving energy via using fly ash material as a friendly environment material, the youth in the village will also be able to study in the evenings, since they typically have to help their parents in farming after school. 


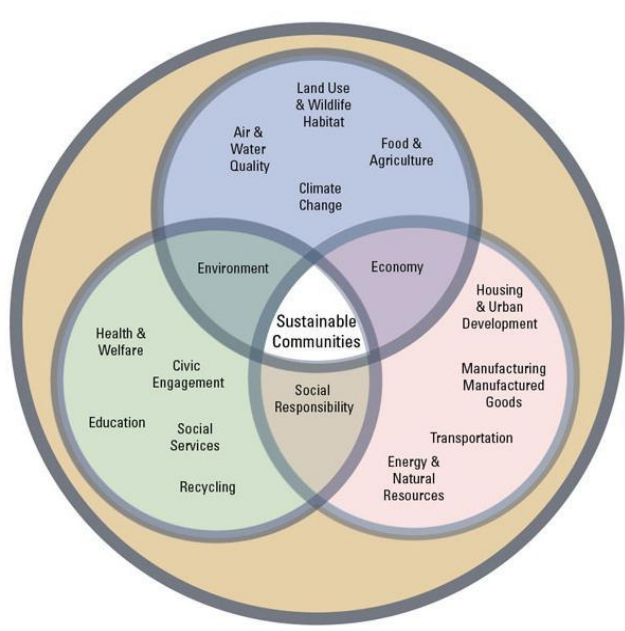

Fig .1. Components of Sustainable Communities [3]

\section{PROJECT DESCRIPTION}

The proposed mechanism is based on three main pillars which fulfill the needs of the local community by finding suitable applications for renewable energy, using the friendly environmental concrete, plaster works, and bricks which use the fly ash material by replacing about $25 \%$ instead of cement in concrete structures and plaster works, and about $60 \%$ of brick ingredients. The third pillar is creating a system (a loop of work) that ensures the attainment of sustainability. By establishing these pillars in a model community, the idea will roll-out to spread through different local communities (governorates) in Egypt.

Locations such as Al-Wadi Al-Jadid and Sinai could be potential areas to apply the proposed approach. That is because both governorates represent more than $50 \%$ of the country's borders. Therefore, their development and growth in population is crucial. Moreover, the low population density and large deserted areas give a way to various possible innovations for the two places and their communities. And also, this facilitates the involvement of the local communities in the planning process for the development projects to be carried out. Some basic information about the two locations, Al-Wadi Al- Jadid and Sinai, work methodology and an outline for the system are as follows:

\section{A. Background}

The first step of this approach is to identify the candidate locations for the study. The selection criteria resulted in two locations that represent important marginalized governorates in Egypt, which are AI-Wadi Al-Jadid and Sinai.

Al-Wadi Al-Jadid governorate is located in the southern west of Egypt. It represents the western border of Egypt with Libya and the southern one with Sudan. The size of the governorate is $440,098 \mathrm{~km} 2$ representing $44 \%$ of Egypt's total area, a considerably large one. The governorate lies at the border of Giza, Marsa Matruh, and El-Menya governorates from the north, Assuit, Sohag, Qena and Aswan from the east. Unfortunately, although it is the largest governorate with regard to area, it is the smallest one with regard to population $(209,597)$.

Figure 2 shows the location of the governorate in Egypt and its surrounding borders and it can be observed that Al-Wadi Al-Jadid represents around $50 \%$ of Egypt's political land borders. $[4,5]$

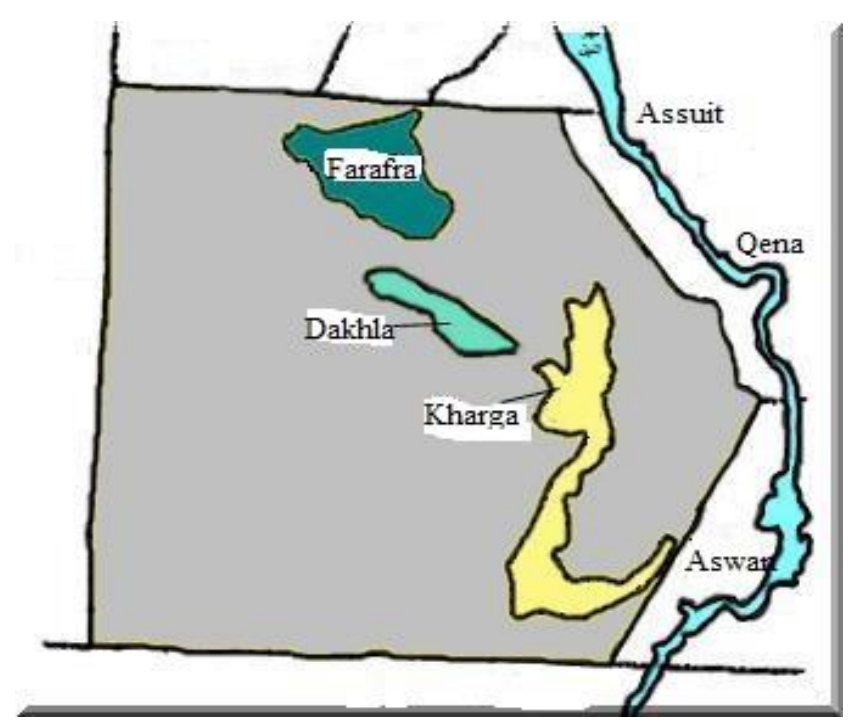

Fig .2. Map showing the location of Al-Wadi Al-Jadid governorate and its surrounding borders

People activities in Al-Wadi Al-Jadid are focused on tourism, agriculture and traditional fabrications. Olives, dates, orange, beans, mango, and apple are the most agriculture productions. Regarding the tourism industry, various touristic sites from different areas are found in the governorate as well as ecotouristic sites, such as Gilf El- Kebir area.In addition, herding sheep and cattle are also one of the main income sources for farmers. On the other hand, fabricating traditional and decorated Pottery, Arabesque, and Kilim rugs are attractive to tourists. In this regard, there are two airports: El-Dakhla airport and El-Kharga airport. 
Concerning available resources, water wells are the main source for water supply. As for electricity, the National Electricity Grid mainly feeds Abu-Tartur mining project to produce phosphate and partially ElKharga, El-Dakhla, El-Farafra, and Paris cities. Meanwhile, other districts distributed in the governorate use diesel to generate electricity for a certain period during the day, maximum 6 hours. This means that people could not use modern energy applications.On the other hand, districts are distributed in different places and are very far from the national grid, ranging between 50 to $210 \mathrm{~km}$, which makes expanding electricity network to these places unviable. So the most applicable solution is to use decentralized systems to feed these districts with its needs of electricity. Tables (1) and (2) list some detailed information on electrical supplies in the governorate.

Table 1. Substations Details at Al-Wadi Al-Jadid Governorate

\begin{tabular}{|c|c|c|}
\hline Substation & $\begin{array}{c}\text { Transmitted Electricity } \\
(\mathrm{W})\end{array}$ & Beneficiary Districts \\
\hline El-Kharga & $163,862,888$ & El-Kharga City and its villages \\
\hline Paris & $10,800,000$ & - \\
\hline Balat & \multirow{2}{*}{$159,086,542$} & Balat City and its villages \\
\cline { 3 - 3 } El-Dakhla & & Moot City and its villages \\
\hline El-Farafra & $14,544,970$ & El-Farafra City and its villages \\
\hline
\end{tabular}

Table 2. Villages and Districts Electricity supplies

\begin{tabular}{|c|c|c|c|c|c|c|}
\hline Date & \multicolumn{4}{|c|}{ Darb El-Arbaeen } & $\begin{array}{l}\text { Balat } \\
\text { City }\end{array}$ & $\begin{array}{c}\text { El-Farafra } \\
\text { City }\end{array}$ \\
\hline \multirow{2}{*}{ Village } & \multicolumn{4}{|c|}{ Bir Alshab } & \multirow{2}{*}{$\begin{array}{l}\text { El-Zayat } \\
\text { Village }\end{array}$} & \multirow{2}{*}{$\begin{array}{l}\text { Ain El- } \\
\text { Teneen }\end{array}$} \\
\hline & $\# 1$ & \#2 & \#3 & \#4 & & \\
\hline No. of Houses & 80 & 80 & 80 & 80 & 46 & 60 \\
\hline $\begin{array}{l}\text { Current source } \\
\text { of electricity }\end{array}$ & - & - & - & - & & \\
\hline $\begin{array}{l}\text { Distance from } \\
\text { the National } \\
\text { Grid of } \\
\text { Electricity }(\mathrm{km})\end{array}$ & 210 & 200 & 190 & 180 & 0.2 & 70 \\
\hline
\end{tabular}

Lack of electrification has proved to be a blocking element against economic and social development. The proof lies in the synergies brought by the electrification of the Nile valley and Delta. Nevertheless, electrification of scattered communities in the Egyptian deserts as well as the construction of friendly environmental concrete structures is a challenge brought in by the financial burden for electrifying and housing the population dispersed over a large geographical area.
However, economic and social development to this population is mandatory to integrate them within the larger society.

The second location, Sinai, is in the eastern side of Egypt falling on the borders with Israel and Palestine and surrounded with the Mediterranean Sea on the north side and the Red Sea from south. It has an area of $60,000 \mathrm{~km} 2$. The land is divided into two governorates, North Sinai and South Sinai. Sinai is renowned as a famous touristic site. Figure 3 shows maps for Sinai Peninsula.

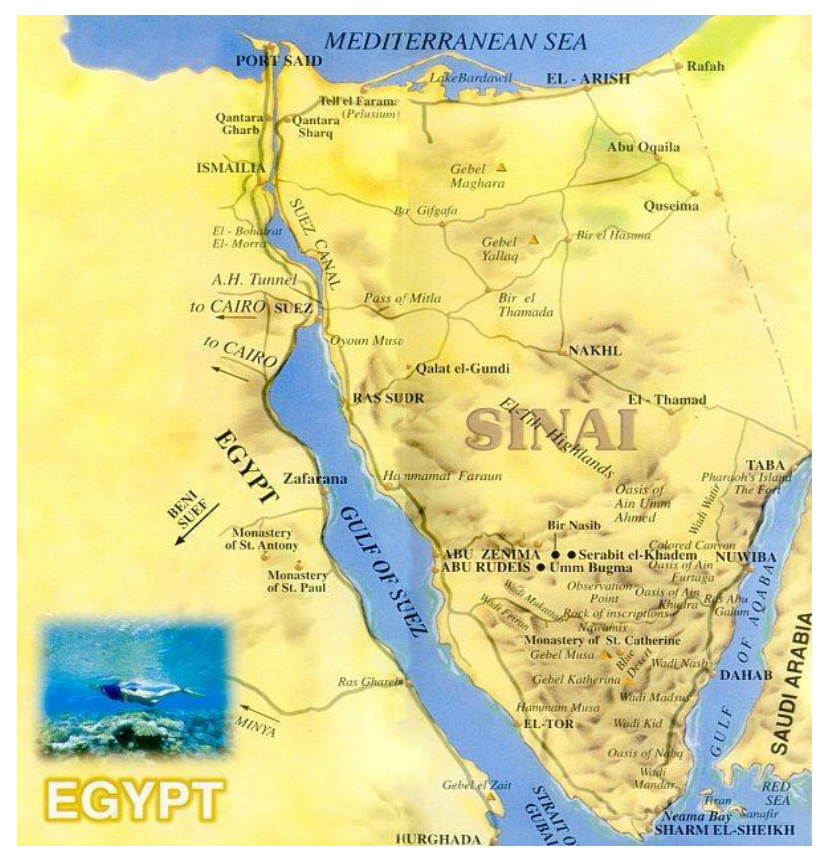

Fig .3. Maps showing location of Sinai Peninsula [6, 7]

North Sinai, where Arish represents its capital city, has a population of 357,900 . It has an illiteracy rate of $24.2 \%$ while the unemployment rate is only $3.8 \%$ yet of which $45.9 \%$ have received higher education degrees. The percentage of people living underneath the poverty line is the same in both North and South Sinai, $11.1 \%$ (earning less than $185 \mathrm{EGP} /$ month).

As for South Sinai governorate, it has a population of 152,500 , which is the lowest population in Egypt, yet it has the highest annual growth rate. The illiteracy rate is $11.6 \%$ in the governorate while the unemployment rate is $7.8 \%$, of which $5.3 \%$ have received higher education degrees. [ ] Al-Tur city is the capital city of South Sinai. 


\section{B. Problem Definition}

The current paper identifies the community needs, land opportunities, using environmentally friendly concrete and bricks in housing projects and models of possible renewable energy applications. In order to reach such a goal, the usage of natural resources needs to be optimized; availablility of both renewable sources of energy and capabilities should be studied, as well as analyzing the society's social and economical needs. Merging both sides in a harmonized scheme socially, economically and environmentally, will lead to a pioneer study able to be replicated in similar communities.

Fundraising need to be partially self-generated. Consequently, the study will attempt to answer how these communities could perform their own economic development based on their resources, capabilities and objectives.

From this context, the available opportunities that lie in Al-Wadi Al-Jadid and Sinai locations are their low population density $-2,12.8$, and 4.8 per $\mathrm{km} 2$ for AlWadi Al- Jadid, North Sinai and South Sinai respectively - with their vast land area that can be used in various projects - agricultural, touristic, etc. that can be replicated in other governorates.It is important to note three main advantages that lie in the choice of these two governorates.

The first advantage is addressing a major problem: a part of Egypt's society has been marginalized for a long time; therefore, such a development project would strengthen their sense of belonging to their country and give them the urge to prove it through their contribution to their larger community. The second one is the location of each governorate, which lies at the borders of the country, making its development and prosperity an important issue for Egypt's security. The last one is developing these communities will be reflected directly into the national GDP, as a result of attracting more tourists.

Figure 4 shows the contributing factors that should be well studied in order to achieve sustainability.

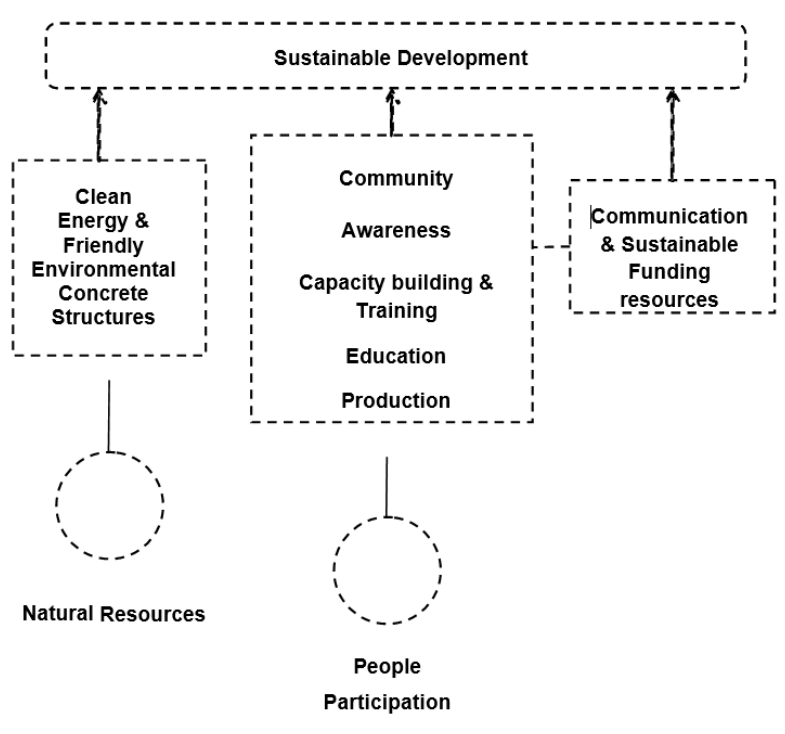

Fig .4. Factors affecting sustainability

\section{Methodology}

The main outline of work is based on building a selfsustained cycle ensuring continuous development while preserving the concept of sustainable development where it is based on three main pillars:

\section{Renewable Energy (RE) System}

One of the principal activities to be taking place is the analysis and design of renewable energy system, whether stand-alone such as solar energy system or a hybrid system consisting of a combination of solar, wind and/or biogas energies. The importance of renewable energy systems lies in the opportunities they offer starting from the ability to expand community facilities and create new jobs to enhancing the quality of life for the society. This cannot be done by national grid expansions due to its high cost, difficulty of planning and needed maintenance which render off-grid renewable energy system a favored substitute. Moreover, it is an already known fact that the national grid is suffering from overload and meeting current demands. Implementation in such deserted community would help promoting awareness on using new and renewable sources of energy in other governorates.

\section{Renewable Energy (RE) System}

Cement industry is the third largest source of environmental pollution, specially the emission of CO2.The fly ash material is a byproduct powder 
resulting from electrical power stations in general and those using coal fuel in particular, as well as the industrial furnaces of steel and iron factories. The fly ash is a powder similar to cement but its particles are very fine and finer than those of cement powder. It is bagged also in bags similar to those of cement and has the same weight (50 kg for each bag). The fly ash is available in Egypt on a large scale. A vast array of possible applications using renewable energy can be carried out. It is an important issue to use the fly ash material in concrete structures and in manufacturing bricks as well as in plaster works. This will reduce about $60 \%$ in the industry of cement production. In addition, this will lead to reducing pollution by preventing emission of about $50 \%$ of CO2. The key issue is finding what is most suitable for the society and its needs concerning jobs creation, filling electrical power needs, looked for expansions and so forth. Of course, this should be done without losing the identity of the community or enforcing a complicated system.

The targeted applications should be carefully chosen through several social surveys and study of land potentials and expected outcomes on the long run. In Egypt, we are using now the fly ash material in the construction of (Metro Tunnels) such as concrete, lining of their interior walls as well as plaster works in order to achieve two targets. The first target is as friendly environmental material and the second target to be used as a fire resistant material. U.S.A, India, Japan, and European countries are the main users of fly ash material in different fields of constructions.

Figures (5-a) and (5-b) illustrate the percentage of fly ash material used in the field of concrete and bricks. The fly ash materials are replaced in concrete and plaster works and bricks instead of cement.

\section{Sustainable Funding Entity}

The continuous improvement is highly dependent on the presence of an entity that can be dedicated to financially support the development and upgrading of the community projects. Such entity could be an existing one (for example a national foundation such as the Social Fund for Development (SFD) or an international organization working on aiding development projects, such as the (World Bank). Creation of a channel between the local community and such proposed entity is to facilitate communication as well as empower local citizens.
In order to reach an effective communication stream, capacity building program will be needed for local citizens where the local government and city councils can play a role in such aspect. A main objective of the study is to design a system that allows the communities to earn income from the renewable energy systems and friendly environmental housing projects in a way that enable them to sustainably finance their future energy systems. The proposal team members have already had positive initial contact with international agencies and local private sector firms who can provide the initial financing and on-going financial support.
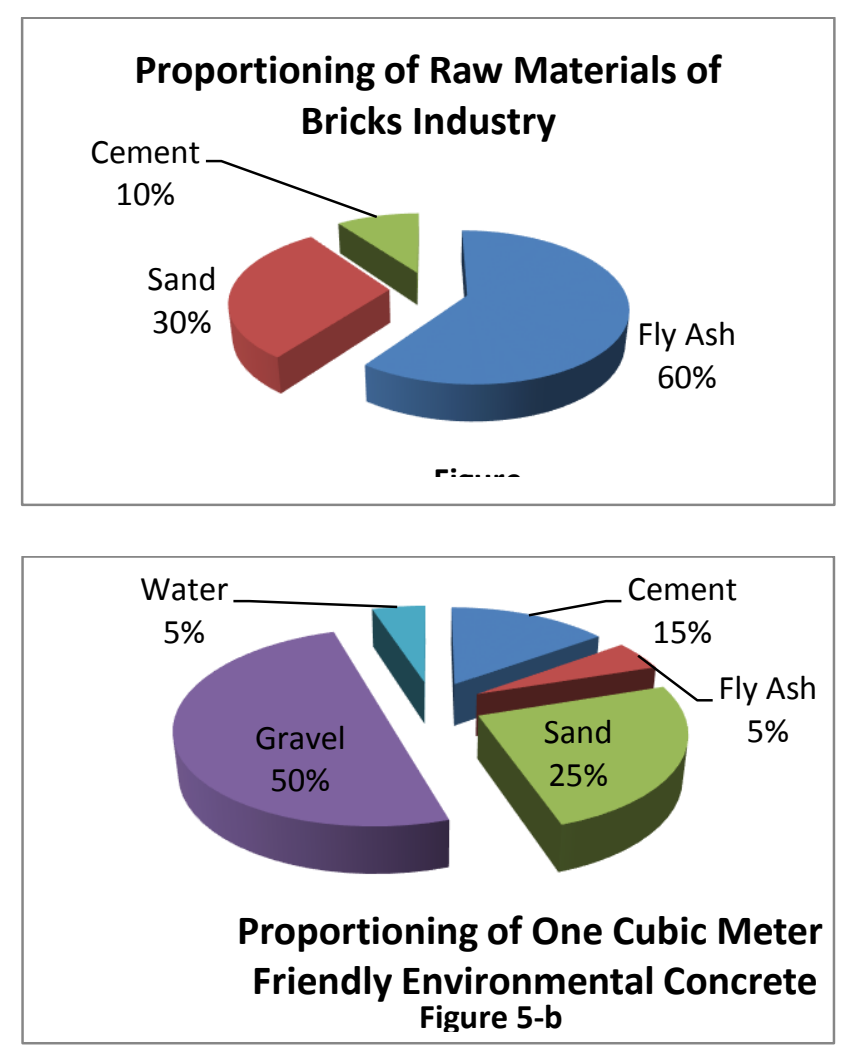

In order to achieve this work cycle, several steps should be taking place:

- Several site visits are expected to take place in order to collect needed data, understand and study the nature of the land, and carry out measurements such as for the nearest cement factories, solar and wind data as well as assess possible locations for implementations

- Social Surveys will be carried out through different forms - meetings, oral and written questionnaires, focus group and so forth. - to analyze the current status of the society concerning educational levels, employment rates, 
main jobs sector as well as knowing the needs of the society including electrical power needed.

- Renewable Resources identification whether solar, wind, biomass, etc: This requires desk research to establish a quantitative data base of the selected site data and to analyze different combinations of hybrid systems and stand-alone ones.

- Energy Requirements identification of both the energy requirement of the settlement together with the load profile: This requires an understanding of the social and economic pattern at the settlement.

- Energy Mix Optimization provided the availability of renewable energy resources data, the availability of using the fly ash material in the industry of cement, the load profile and generation requirements. A techno- economic study shall be performed to provide the most economic generation mix together with the least Loss of Load Probability. Homer software is one candidate for this study.

- Technology Selection and Project Financial Feasibility Study where translating the proposed generation mix into technology is governed by the simplicity of the adopted technology together with its economics. The primary selection of the technology is dependent on its simplicity and suitability to the population. The second selection that follows is the prefeasibility of the project. Rest screen shall be used to perform the pre- feasibility study of the optimum generation mix.

- Project Generalization is based upon the obtained results which shall be generalized so that they can be used with other settlements. This requires carrying out sensitivity analyses. The results shall be summarized in user friendly tables and charts.

- Project Engineering Equipment Specifications and cost estimates as well as cost benefit analysis of the project shall be prepared by the project team. The provided document shall be the basis for the future tender for the actual implementation of the project.

\section{CONCLUSION}

The main outcomes that this project is looking for can be summarized in the following points:

- Using environmentally friendly concrete structures and bricks via replacing the material of fly ash instead of about $25 \%$ of cement in concrete structures and about $60 \%$ of bricks ingredients, which should lead to reducing the emission of about $50 \%$ of $\mathrm{CO} 2$. This will lead to keeping on the heat of indoor houses and consequently saving energy.

- Satisfying community needs through the implementation of renewable energy systems that meet the required growth and prosperity of land and society.

- Empowering local citizens by offering needed guidelines, training and capacity building to be able to take decisions needed to help their community and reserve the environment which they live in.

- Introduce a talent fundraising approach.

- Promoting sustainability awareness by giving AlWadi Al-Jadid and Sinai as model governorates for a sustainable community.

- Promoting the use of renewable energy and fly ash systems where Egypt has great potentials in that field. This could help in solving electricity shortage problems and reduce the load on the national grid by using off-grid energy systems for remote areas and reducing the emission of $\mathrm{CO} 2$ via preventing the production of about $50 \%$ of cement.

- Helping in improving the quality of Egypt's tourism sector as well as increasing its revenue.

- Developing a replicable sustainable model.

- Develop an evaluation scheme based on monitoring socio-economic parameters during different implementation phases. 


\section{REFERENCES}

[1] International Institute for Sustainable Development (iisd); http://www.iisd.org/sd/

[2] The Egan Review: Skills for Sustainable Communities

http://dera.ioe.ac.uk/11854/1/Egan_Review.pdf

[3] Sustainable Communities Components; http://goo.gl/1OSCQ

[4] Al-Wadi Al-Jadid Governorate official site; http://www.newvalley.gov.eg/html/nabza1.htm

[5] Luventicus Academy of Sciences; http://www.luventicus.org/maps/egypt/newvalley governorate.html
[6] Map of Sinai Peninsula; http://goo.gl/DDBK9

[7] Map of Egypt; http://goo.gl/UXGdg

[8] Egypt Human Development Report 2010 UNDP

[9] CLAYTON, N., and LENNON, T. High-grade concrete columns in fires. Concrete. Vol. 34, No.3. March 2000, p.51.

[10] THOMAN, T., When Hull freezes over. Tunnels and Tunneling International, Vol. 32, No.10. October 2000, pp. 16-17

[11] THE CONCRETE SOCIETY. Design guidance for high strength concrete. Technical Report 49, 1998, $176 \mathrm{pp}$. 